\title{
CRISES, DISPUTAS E RESISTÊNCIAS: OS TERRITÓRIOS TRADICIONAIS DAS COMUNIDADES PESQUEIRAS E QUILOMBOLAS DA ILHA DE MARÉ - BA
}

\section{Crises, disputes and resistance: the traditional territories of fishing communities and quilombolas in the Maré Island - BA}

Kássia Aguiar Norberto Rios Universidade Federal do Recôncavo da Bahia - UFRB

\section{Informações do artigo}

Recebido em 02/09/2020

Aceito em 09/og/2020

doi>: https://doi.org/10.25247/2447-861X.2020.n251.p716-741

Esta obra está licenciada com uma Licença Creative Commons Atribuição 4.0 Internacional.

\section{Como ser citado (modelo ABNT)}

RIOS, Kássia Aguiar Norberto. Crises, disputas e resistências: os territórios tradicionais das comunidades pesqueiras e quilombolas da llha de Maré - BA.

Cadernos do CEAS: Revista Crítica de Humanidades. Salvador/Recife, v. 45, n. 251, p. 716-741, set./dez. 2020. DOI: https://doi.org/10.25247/2447-861X.2020.n251.p716-741

\begin{abstract}
Resumo
Este artigo tem por objetivo apresentar uma análise do cenário de crises, disputas e resistências que envolve as comunidades tradicionais pesqueiras e quilombolas da Ilha de Maré, Salvador - Bahia. Uma das temáticas que tem ganhado relevante destaque, nas últimas décadas, refere-se às inúmeras disputas e conflitos territoriais que as comunidades tradicionais pesqueiras têm vivenciado nos seus territórios. No estado da Bahia esse cenário envolve cerca de 600 comunidades e mais de 100 mil famílias, dentre as quais destacamos aquelas situadas na llha de Maré, localizada na Baía de Todos os Santos (BTS). Possuidoras de um amplo conhecimento sobre as águas, os manguezais e os pescados da BTS, a relação de apropriação desenvolvida por essas comunidades com a natureza é caracterizada por extremos laços de identidade, pertencimento e, principalmente, respeito, onde são desenvolvidos valores simbólicos e materiais que asseguram o seu modo de vida e configuram suas territorialidades. Territorialidades que têm sido intensamente ameaçadas e, em alguns casos, destruídas, pelo modelo de desenvolvimento historicamente empregado no local. Observa-se que os espaços que eram de uso das comunidades, aos poucos, foram sendo ocupados, delimitados e controlados por novas e distintas atividades (aquícola, portuária, metalúrgica, petroquímica, turística etc.), originando inúmeras crises sociais, econômicas, ambientais, além das disputas territoriais. Para o desenvolvimento da análise, recorremos metodologicamente às técnicas da pesquisa participante com a utilização dos seguintes instrumentos: levantamento bibliográfico, documental e, principalmente, de campo, com a realização de reuniões, participação em audiências públicas, oficinas de geografia e cartografia, mapeamento e georreferenciamento dos territórios em disputa.
\end{abstract}

Palavras-Chave: Crises. Disputas. Resistência. Territórios. Pesca.

Abstract

This paper aims to present an analysis of the crisis's, disputes' and resistance's scenariosthat involves the traditional fishing and quilombola communities of Maré Island, Salvador - Bahia.Certain issue that has gained relevant prominence in the last decades, refers to the countless territorial disputes and conflicts that traditional fishing communities have experienced in their territories. In the Bahia State, this scenario involves about 600 communities and more than 100 thousand families, among which we highlight those located on Marélsland, located in the Todos os Santos Bay (TSB). These communities have a broad knowledge of the waters, mangroves, and fishes of TSB. The relationship of appropriation developed by these communities with Nature is based onprofound ties to identity, belonging feelings and, above all, respect, where symbolic and materials that ensure their way of life and configure their territorialities. Territorialities that have been intensely threatened and, in some cases, destroyed, by the development model that has been historically employed on the site. We observed places that were used by the communities in which were gradually being occupied, delimited, and controlled by new and distinct activities (aquaculture, port, metallurgy, petrochemical, tourism, etc.). This led to numerous social, economic, and environmental crises, in addition to territorial disputes.For the development of analytical goals, we used methodologically the techniques of action-research using the following instruments: bibliographic, document registration and mainly field surveys, with meetings, joining in public hearings, geography and cartography workshops, mapping and georeferencing disputed territories.

Keywords: Crises. Disputes. Resistance. Territories. Fishing. 


\section{Introdução}

Uma das temáticas que tem ganhado relevante destaque, nas últimas décadas, refere-se ao cenário de inúmeras disputas e conflitos territoriais que as comunidades tradicionais pesqueiras têm vivenciado nos seus territórios. No estado da Bahia esse cenário envolve cerca de 600 comunidades e mais de 100 mil famílias, dentre as quais destacamos aquelas situadas na llha de Maré, localizada na Baía de Todos os Santos (BTS), recorte empírico analítico desse artigo.

Na Ilha de Maré, pode-se dizer que esse cenário tem origem ainda no século XVI, quando da ocupação do Recôncavo Baiano por inúmeros engenhos de cana-de-açúcar e fazendas. Com a chegada dos portugueses e, posteriormente, a constituição dos primeiros engenhos, deu-se início a um longo processo de ocupação das terras que configuram, hoje, os municípios localizados no entorno da BTS, a incluir as Ilhas de Maré, dos Frades, entre outras.

A inserção dos engenhos e fazendas na llha, além de demarcar a "propriedade privada das terras", ocasionou a expulsão de inúmeros indígenas e campesinos livres. Fato que se intensificou/consolidou no ano de 1850, com a Lei de Terras. De acordo com os moradores da Ilha, nesse período, cerca de $60 \%$ do território local já se encontrava nas mãos dos senhores de engenho e alguns fazendeiros. Décadas depois, com a abolição da escravatura, no ano de 1888, e o declínio da indústria açucareira, novos processos de ocupação da terra são desenvolvidos, em especial pela atividade da agricultura e pecuária. Nesse período, muitos senhores de engenho comercializaram parte de suas terras com fazendeiros da região, além da ocupação de outras áreas de mata por "novos proprietários".

É desse processo de ocupação/comercialização de terras que surgem as primeiras crises e disputas territoriais, envolvendo, principalmente, os "quilombos" - constituídos em Maré- e os fazendeiros que reivindicavam a propriedade da terra.

Observa-se que os acontecimentos/processos históricos ocorridos na época (Lei Terras, abolição da escravatura, decadência da indústria açucareira e novos processos de ocupação de terras desencadeados pela agricultura e pecuária) conformaram um novo cenário, quando inúmeros ex-escravos e campesinos livres encontravam-se sem terra e/ou sem trabalho. Na época, a alternativa existente era o trabalho nas fazendas, no qual as 
relações estabelecidas "eram baseadas no arrendamento da terra e na cessão da parte da produção ao dono do terreno. Quando da chegada de um trabalhador de fora para trabalhar no local, era costume dos fazendeiros cederam um pedaço de terra para o estabelecimento da roça" (INCRA, 2016b, p. 98). "Os donos diziam que as terras eram deles e se quiséssemos ficar, tínhamos que trabalhar e pagar o arrendamento. Como tínhamos família e precisávamos de um lugar para morar e trabalhar, era isso ou nada!" (DEPOIMENTO PESCADOR DA ILHA, 2016).

As diversas imposições feitas aos trabalhadores e a exploração nas relações de trabalho foram os motivos que levaram à ocorrência de inúmeras disputas entre posseiros e fazendeiros. Pois, não existia, para os trabalhadores, "nenhuma segurança em relação à apropriação da produção e nem de continuidade no local, apesar da presença centenária, desde o tempo dos pais, avós e, em alguns casos, bisavós" (INCRA, 2016b, p. 98).

As constantes ameaças, a insegurança e a exploração realizada pelos fazendeiros ocasionaram, na década de 1960, uma intensificação dos conflitos existentes, liderados, em parte, pelos "Cachoeiranos" (grupo de trabalhadores que vieram do município de Cachoeira para trabalhar e residir na llha) que, revoltados com a situação vivenciada, questionavam e se negavam a aceitar tais arbitrariedades. A destacar: expulsão dos posseiros; obrigação de entrega de toda a produção; destruição de roças por gados dos fazendeiros; incêndio nas casas, prisões etc. (INCRA, 2016b).

Foi a partir da presença dos Cachoeiranos que muitos trabalhadores da Ilha deixaram de pagar o arrendamento e de entregar parte de sua produção, ocasionando novos conflitos com os fazendeiros. Como consequência, muitos posseiros foram expulsos, enquanto outros abandonaram suas roças, passando a se dedicar à pesca e à mariscagem, tendo como atividades complementares o extrativismo e a pequena agricultura nos "quintais das casas". É desse cenário que decorre o declínio da atividade da agricultura na llha.

Todavia, mesmo com o declínio da atividade, a Ilha de Maré, ainda hoje, é ocupada por diversas fazendas, que abrangem cerca de $70 \%$ do território local. Algumas destas se resumem a pastos e matas, outras são utilizadas pelas comunidades para a pequena agricultura e alguns posseiros para comércio e serviços. É importante destacar que a ideia de "propriedade das terras aos fazendeiros" ainda permanece, negando os direitos territoriais das comunidades tradicionais locais (INCRA, 2016b). 
Além dos conflitos com os fazendeiros, outras disputas territoriais passaram a existir na Ilha, no decorrer dos anos, principalmente, a partir das décadas de 1940 e 1950, quando tiveram início as atividades de extração e tratamento do petróleo. Deste então, foram inseridos próximo à llha de Maré mais de 300 empreendimentos, contendo indústrias, terminais portuários privados, dutos, cais, tanques de armazenamento de produtos químicos, instalações petrolíferas, entre outros (SARAIVA, 2008; CARNEIRO et al, 2014).

As disputas e os conflitos que antes ocorriam no interior da llha se diversificaram e se expandiram para toda a área da BTS, tendo influência direta no território pesqueiro local. "Há evidências científicas de que o meio ambiente de trabalho de marisqueiras e pescadores artesanais de llha de Maré está quimicamente contaminado, inclusive com risco toxicológico e carcinogênico para a saúde humana" (CARVALHO et al, 2014, p. 6).

Em pesquisa apresentada no Mapa de Conflitos envolvendo Injustiça Ambiental e Saúde no Brasil, no ano de 2014, sobre os diversos conflitos vivenciados pelos pescadores artesanais da Ilha, as seguintes denúncias foram destacadas:

(1) poluição hídrica e atmosférica; (2) irregularidades ambientais derivadas da falta de licenciamento do porto; (3) falta de atuação dos órgãos ambientais; (4) ausência de estudos relacionados aos riscos a que a população local estaria exposta face à poluição provocada pelas indústrias químicas ali instaladas; (5) impactos ambientais provocados pela dragagem, processo que estaria provocando a mortandade de peixes e prejudicando os pescadores (MIASB, 2014, p. 1).

Além das denúncias, a pesquisa ainda destaca como esses conflitos têm alterado o regime tradicional de uso e ocupação do território, a forma com que as comunidades têm lutado contra as "práticas de racismo ambiental" vivenciadas historicamente e, principalmente, a falta/irregularidade na demarcação dos territórios tradicionais.

Das 11 comunidades existentes na Ilha, 6 são certificadas pela Fundação Cultural Palmares como quilombolas e encontram-se, desde o ano de 2004, com processo de regularização territorial em tramitação nos órgãos competentes. A demora na regularização, a ineficácia/inexistência das legislações existentes e a constante "valorização espacial" da BTS têm contribuído para a inserção de distintas e novas atividades na Baía e, com isso, condicionado as comunidades locais a uma nova dinâmica de uso, controle e acesso ao território. 
Observa-se que é desse cenário que surge o histórico de crises vivenciado pelas comunidades tradicionais da llha de Maré, que, por vez, se materializa em inúmeras disputas e os conflitos territoriais, e demanda a construção de diversas ações de resistência. Os (as) pescadores (as) têm buscado, no decorrer do tempo, além da regularização territorial e efetivação de seus direitos, manter viva a cultura, a identidade e os laços de pertencimento que caracterizam as suas territorialidades (MPP, 2012).

É nesse contexto que se objetiva, no presente artigo, apresentar uma análise do cenário de crises, disputas e resistências que envolve as comunidades tradicionais pesqueiras e quilombolas da Ilha de Maré, Salvador - Bahia. Não obstante, apresentaremos também as principais estratégias de luta e defesa empreendidas, a destacar o processo de regularização territorial quilombola.

Para o desenvolvimento da análise, recorremos metodologicamente às técnicas da pesquisa participante (BRANDÃO; BORGES, 2007) com a utilização dos seguintes instrumentos: levantamento bibliográfico, documental e, principalmente, de campo com a participação em audiências públicas, grupos de discussão, oficinas de geografia e cartografia; confecção de mapas temáticos; realização de entrevistas e rodas de conversa e, principalmente, o georreferenciamento do território local.

\section{As principais disputas e os conflitos territoriais existentes}

O progresso do governo é acabar com as comunidades tradicionais. Progresso mesmo é plantar na terra. Progresso mesmo é pescar no mar. Progresso mesmo é pescar nos rios. Os pescadores é que vão gostar. Progresso mesmo é cuidar da terra. Progresso mesmo é cuidar do mar. Progresso mesmo é cuidar dos rios. A natureza é que vai gostar. Progresso mesmo é não cortar as matas. Progresso mesmo é não cortar os mangues. Progresso mesmo é preservar os rios. A natureza é que vai gostar. (O Progresso do Governo - Ernandes Carlos Lopes $^{1}$ )

O trecho da música apresentado traduz a forma com que as comunidades tradicionais pesqueiras da llha de Maré compreendem os diversos processos de transformação ocorridos,

\footnotetext{
${ }^{1}$ Música "O progresso do Governo" de autoria de Ernandes Carlos Lopes, pescador, Ilha de Maré (BA).
} 
historicamente, na BTS e, por consequência, em seus territórios. O discurso do progresso e do desenvolvimento foi e tem sido utilizado até os dias atuais, como estratégia para a ocupação e inserção de distintas atividades no entorno da Baía. Entretanto, trata-se de uma ideia de progresso que não condiz com a realidade e as necessidades das comunidades tradicionais locais, pelo contrário, compromete diretamente a sua sobrevivência.

O território articulado das comunidades pesqueiras da llha de Maré abrange cerca de $65 \%$ da área da BTS, o que inclui faixas de terras, manguezais, apicuns, coroas, rios, ilhas, ilhotes etc. Observa-se que as transformações ocorridas na BTS, além de ter comprometido as condições naturais da baía, têm proporcionado diversos impactos (sociais, ambientais, culturais e econômicos) às comunidades locais. Daí o surgimento de inúmeras disputas e conflitos territoriais.

Na Ilha de Maré, a eminência dessas disputas pode ser analisada a partir de dois grandes recortes espaços-temporais:

a) do momento de ocupação da llha (século XVI) até a chegada da Petrobrás no Recôncavo Baiano (década de 1950); e,

b) da chegada da Petrobras aos dias atuais, com destaque para implantação do CIA e da Base Naval.

O processo de ocupação da Ilha ocorreu em um período histórico, caracterizado pelo tripé latifúndio, monocultura e escravidão. É de um modelo de sociedade senhorial, baseado na propriedade de terras e negros escravizados que surgem diversas disputas e conflitos territoriais, a destacar: a resistência indígena no processo de ocupação, a exploração dos negros escravos pelos senhores dos engenhos e as ameaças e expulsões de posseiros pelos fazendeiros.

A inserção dos engenhos de cana-de-açúcar e, posteriormente, de algumas fazendas na Ilha, além de ter demarcado uma "privatização do espaço", definiu diversas relações de poder, dentre as quais cabia aos senhores dos engenhos e fazendeiros a "propriedade da terra" e o "controle/definição das relações de trabalho", marcadas até o ano de 1988 pela escravatura e, após a libertação dos escravos, pela exploração e ameaça de posseiros.

De acordo com os relatos dos moradores mais antigos, os indígenas que habitavam a Ilha tentaram resistir por algum tempo à colonização portuguesa, entretanto, acabaram 
sendo dizimados ou escravizados. Enquanto escravos e submetidos a relações de exploração e maus tratos, indígenas e negros africanos vivenciaram inúmeros conflitos com os senhores dos engenhos e capitães do mato, que, cotidianamente, os vigiavam, ameaçavam e agrediam.

Com a libertação dos escravos no ano de 1988, os conflitos não cessaram, pelo contrário, ganharam novas formas e sujeitos. O declínio da indústria açucareira no Recôncavo Baiano levou vários senhores de engenhos a abandonar ou vender suas terras a fazendeiros da região que se dedicavam à agricultura e à pecuária. Na llha de Maré, esse processo ocasionou a ocupação de inúmeras terras que, até então, eram utilizadas pelos trabalhadores camponeses e comunidades quilombolas. Surgem, então, novos conflitos por terra.

Sem trabalho e local para moradia, ex-escravos e camponeses passaram a trabalhar nas "novas fazendas", mais especificadamente, a partir do arrendamento da terra e cessão da parte da produção ao dono do terreno. É no âmbito dessa relação de trabalho que se originam outros e novos conflitos. Mesmo após a abolição da escravatura, os fazendeiros continuaram a tratar os trabalhadores a partir de ameaças e exploração. Inconformados com o histórico vivenciado e cada vez mais expostos a arbitrariedades, os trabalhadores se negaram a aceitar tal situação, ocasionando diversos conflitos: expulsões, queima de casas, destruições de plantações, prisões, ameaças etc.

De acordo com os moradores mais antigos, a insegurança e os conflitos eram as principais questões que incomodavam os trabalhadores, pois, não havia nenhuma garantia da produção e permanência nas fazendas. "A qualquer hora o fazendeiro chegava e expulsava os posseiros, soltava os animais dele para destruir as roças e exigia mais que o combinado. Era muita ameaça e quando menos esperava, já tinha outro posseiro no lugar" (DEPOIMENTO PESCADOR DA ILHA - Pesquisa de Campo, 2017). Um cenário que perdurou na llha até o final da década de 1990, quando algumas comunidades se organizaram e solicitaram à Fundação Cultural Palmares a certificação quilombola, obtendo-a no início da década de 2000. A partir de então, se negaram a pagar o arrendamento aos fazendeiros.

Mesmo com o novo cenário, a agricultura desenvolvida na llha já se encontrava fortemente comprometida, pois, muitos posseiros, cansados das ameaças e conflitos, abandonaram suas terras e passaram a se dedicar exclusivamente à pesca artesanal e à 
mariscagem. A agricultura, que foi, por décadas, a principal atividade econômica na Ilha, passou a ser desenvolvida em pequenas roças, visando basicamente ao consumo familiar.

É importante destacar que é no decorrer desse período que se conforma grande parte da organização sócio espacial hoje existente na Ilha, marcada, principalmente, pela presença de grandes fazendas, inúmeras propriedades particulares e áreas de posse. Atualmente, a estrutura fundiária da Ilha é composta por aproximadamente 72 propriedades, que, de acordo com o levantamento realizado junto às comunidades, ao INCRA e à SPU/BA, referem-se a: cerca de 8 fazendas; várias áreas menores desmembradas destas fazendas e, em nome de familiares e/ou posseiros, diversas propriedades particulares registradas em Cartório (INCRA, 2017; SPU, 2017). Sobre estas propriedades cabe destacar que muitas se resumem a áreas de pastos e matas, outras são utilizadas pelas comunidades para a pequena agricultura e algumas são utilizadas por posseiros não-quilombolas para moradia, agricultura, comercio e/ou serviços.

As comunidades, por vez, se encontram inseridas no interior das fazendas, nos arredores e, principalmente, nas áreas consideradas como "bordas" da Ilha. "Aqui na comunidade as famílias vão crescendo e com isso tem a necessidade de aumentar as casas. Como para dentro tem as cercas, algumas famílias acabaram construindo suas casas nas bordas, algumas em áreas não indicadas (apicum, mata etc.)" (DEPOIMENTO PESCADOR DA ILHA Pesquisa de Campo, 2017).

Cabe destacar, também, a existência das pequenas propriedades, pertencentes, também, a posseiros não quilombolas da Ilha e que se encontram espalhadas em diversas áreas do território. É desse cenário que emergem algumas das insatisfações das comunidades, principalmente em relação à "falsa ideia" de estarem ocupando terras de particulares.

Em síntese, esse é o cenário que marcou as principais disputas e conflitos territoriais existentes "no interior da Ilha" até meados do século XX. O destaque para o interior refere-se à forma com que as comunidades compreendem, historicamente (temporalmente), os conflitos vivenciados antes e após a chegada da Petrobrás na BTS (década de 1950). Para estas, a criação da Refinaria Nacional do Petróleo em Mataripe/São Francisco do Conde posteriormente denominada Refinaria Landulpho Alves (RLAM) - na década de 1950, 
demarca o início de novos e distintos conflitos, que não se restringem mais ao interior da Ilha, porém, interferem diretamente no desenvolvimento de suas atividades.

O território articulado das comunidades tradicionais pesqueiras da llha de Maré envolve cerca de $65 \%$ da área da BTS (Figura 01). Trata-se de distintos espaços e ambientes que têm sido historicamente apropriados pelos pescadores, como forma de garantir a sua sobrevivência e reprodução social.

É sabido que o processo de degradação observado atualmente na BTS é histórico e remete ao século XVI, quando da "construção da primeira capital do Brasil, Salvador, mediante a implantação em larga escala dos engenhos de açúcar de cana e da construção de diversos navios e portos" (CARVALHO et al, 2014, p. 4016). Entretanto é com a descoberta do petróleo, em 1930, e o início das obras de construção da RLAM, em 1949, no estuário do rio Mataripe, que ocorre uma aceleração no processo de degradação ambiental da BTS (PEIXOTO, 2008; CARVALHO, 2014).

Como o início da exploração de Petróleo na BTS e a construção da RLAM, novas e distintas atividades dos diversos setores foram inseridas na região: indústrias alimentícias, química, portuária, automobilista, imobiliária, turística, aquícola, portos, estaleiros etc. Desde a década de 1950, mais de 250 atividades foram inseridas no local. Tal processo, aliado a uma conjuntura política estadual de constantes incentivos à industrialização, em especial na zona costeira, levou a BTS a ser considerada, atualmente, uma das áreas mais antropizadas do Estado e onde se concentra o maior índice de conflitos envolvendo comunidades tradicionais pesqueiras (MPA; BAHIA PESCA, 2010; MPP, 2015).

No momento em que essas atividades foram inseridas na BTS, inúmeras mudanças também foram ocasionadas na vida das comunidades locais, seja pelas condições ambientais da própria baía e/ou pela ocupação dos espaços historicamente apropriados para o desenvolvimento da pesca e da mariscagem. Tais considerações expõem a dimensão política desses territórios, uma vez que seu uso, apropriação e controle são de interesse de diferentes grupos sociais e atividades produtivas. Essa dimensão faz com que se explicitem disputas políticas que, por vez, emergem novas disputas territoriais.

Na llha de Maré essas disputas são diversas e envolvem: o agronegócio com monocultivo do eucalipto; a carcinicultura; a instalação de indústrias automobilística, 
alimentícia; farmacêutica; metalúrgica; petroquímica; fábricas de argamassa e cimento, termoelétricas; portos e terminais de uso privativo, estaleiros, empreendimentos turísticos, etc. Ao observarmos a Figura 01, onde consta a espacialização das principais disputas e conflitos vivenciados pelas comunidades da Ilha de Maré sobre o território articulado (terra e água), notaremos que a maioria dos conflitos pontuados encontra-se inserida diretamente no território pesqueiro local. Trata-se de distintas atividades que, ao ocuparem a BTS, impuseram uma nova dinâmica de uso e controle do espaço que se distingue e foge do controle das comunidades. 
Figura 01 - Mapa das principais disputas e conflitos territoriais vivenciados pelas comunidades tradicionais pesqueiras no território articulado (terra e água) da llha de Maré (BA), 2017.
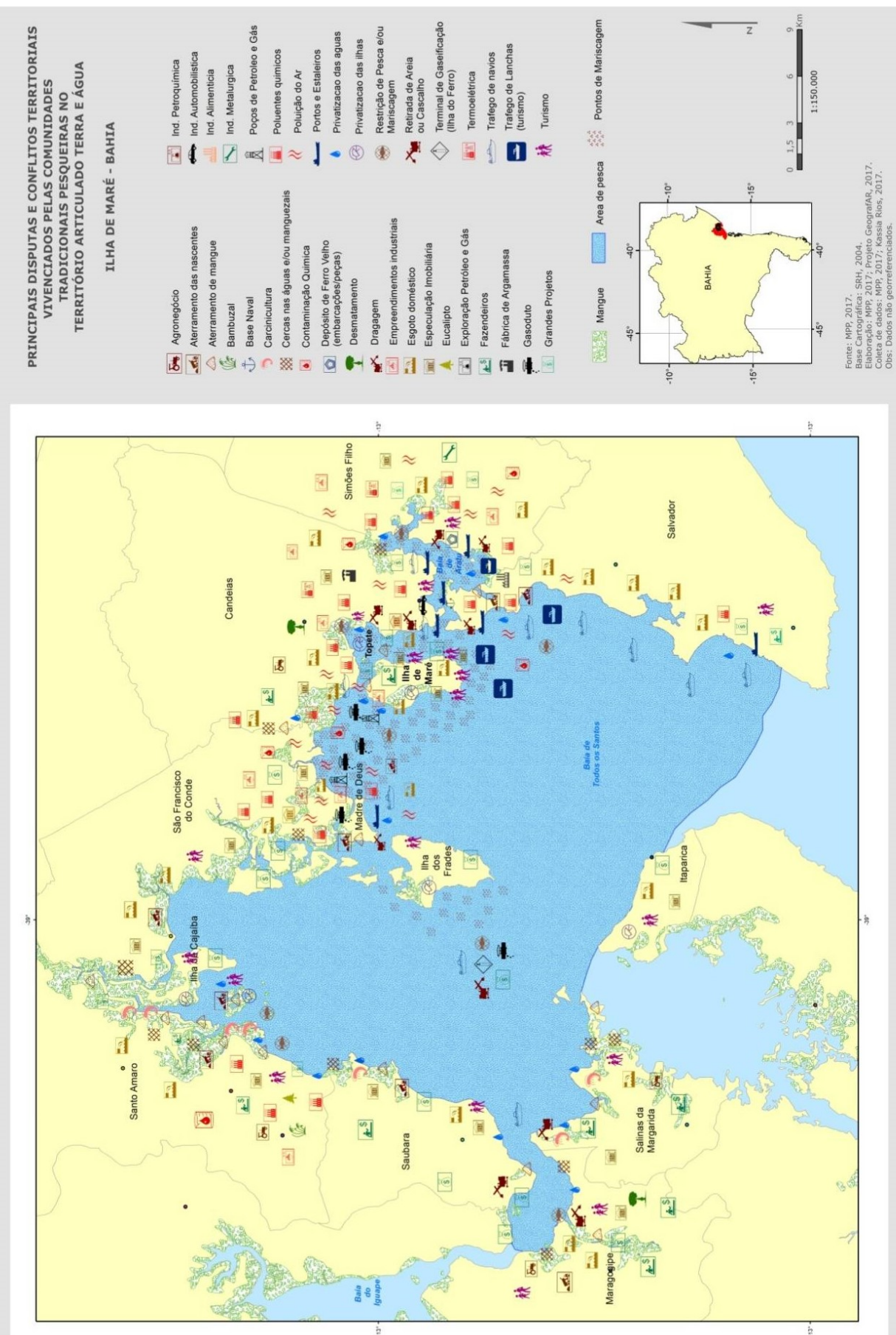

Fonte: MPP, 2017

Para Acselrad (2004, p. 26), a maioria desses conflitos envolve grupos sociais que possuem formas diferenciadas de apropriação, uso e significação do território. Sua origem ocorre "quando pelo menos um dos grupos tem a continuidade das formas sociais de 
apropriação ameaçada por impactos indesejáveis - transmitidos pelo solo, água, ar ou sistemas vivos - decorrentes do exercício das práticas de outros grupos".

Nessa mesma linha, Prost (2009, p. 7) acrescenta que esses conflitos "despontam quando vinga uma divergência de interesses ao passo que se tem a apropriação de parte do meio ambiente, comum na sua origem e essência, por um grupo social privatista". Na llha de Maré, os conflitos existentes têm como principal base: a privatização do espaço e a degradação ambiental ocasionada na região, em decorrência da inserção/funcionamento dos novos empreendimentos.

\section{A chegada da "Petrobrás na BTS" e o início de novos e distintos conflitos}

A instalação da Refinaria Landulpho Alves (RLAM) em Mataripe, na década de 1950, representa, para as comunidades da Ilha de Maré, o início de novos e distintos conflitos. Denominada inicialmente de Refinaria Nacional do Petróleo, "em 1953, com a criação da Petrobras, esta foi incorporada à recém criada companhia, sendo rebatizada em 1957, em homenagem ao engenheiro agrônomo e político baiano que lutou pela causa do petróleo no Brasil" (PETROBRAS, 2016, s/n).

Considerada a "segunda maior refinaria em complexidade e em produção no Brasil, a RLAM está instalada no entorno do Rio Mataripe e tem instalações em toda a região de manguezal do rio São Paulo" (MONTEIRO, 2014, p.43). Atualmente, suas atividades e os procedimentos operacionais encontram-se em grande percentual automatizados, "tendo como principais produtos os seguintes derivados: propano, propeno, iso-butano, gás de cozinha, gasolina, nafta petroquímica, querosene, querosene de aviação, parafina, óleo combustível e asfaltos" (PEIXOTO, 2008, p. 127).

De acordo com Peixoto (2008, p. 97), com a instalação da RLAM "se inaugurou um novo ciclo econômico de desenvolvimento no estado da Bahia, com a atividade industrial virando a página da até então reinante agroindústria da cana-de-açúcar". Para as comunidades da llha de Maré, esse novo ciclo se caracteriza "pela massiva invasão e destruição", dos territórios historicamente ocupados pelas comunidades tradicionais da região. 
É importante destacar que as instalações da RLAM encontram-se inseridas dentre os múltiplos espaços que envolvem o território articulado local, sendo estes considerados pelas comunidades, como de grande potencial para a captura de mariscos e pescados. Segundo Monteiro (2014, p. 54), a implantação da refinaria ocasionou "duas situações que confrontam com o modo de vida e com a atividade de pescaria artesanal e mariscagem: o impedimento em acessar regiões tradicionalmente utilizadas e a contaminação dos recursos pesqueiros e ambientes".

Em estudo realizado por Peixoto (2008), foi apontado que as atividades e operações da RLAM, entre outras indústrias, têm ocasionado perdas da biodiversidade e contaminação química dos solos e corpos hídricos. Nas regiões onde se encontram as instalações da refinaria, a destacar nos rios Mataripe e São Paulo "os recifes de corais e os manguezais [...] encontram-se bastante comprometidos, com vegetação fortemente degradada pelo uso intensivo a que foi exposto (PEIXOTO, 2008, p. 161). Tal constatação também é realizada pelas comunidades da llha, quando apontam uma redução na quantidade/qualidade dos peixes e mariscos capturados, nas proximidades da refinaria. Para estas, desde a inserção da RLAM, os rios Mataripe e São Paulo têm sofrido grandes alterações ambientais.

A descoberta do petróleo e, posteriormente, inserção das indústrias, ocasionou a invasão e a perda de diversos espaços que compõem o território pesqueiro local. Desde a década de 1950, foram instalados diversos poços de petróleo na Baía e em algumas comunidades da Ilha de Maré. De acordo com as comunidades, são 14 poços da Petrobrás distribuídos em terra e água. Os poços de terra encontram-se localizados nas comunidades de Martelo, Porto dos Cavalos Ponta Grossa e Maracanã, já os de água, assim como os dutos para o escoamento da produção, encontram-se inseridos no mar, em áreas (coroas, pesqueiros) bastante utilizadas pelas comunidades para a captura de peixes e mariscos.

Ainda de acordo com as comunidades, a Petrobrás invadiu o território local, abriu estradas, inseriu píers, construiu poços e dutos para o escoamento do produto e, após isso, "abandonou" o espaço. Os moradores das comunidades de Martelo e Porto dos Cavalos denunciam que a área onde se encontra parte dos poços em terra está abandonada e com os equipamentos degradados, ou seja, em condições que podem comprometer diretamente a segurança da comunidade. Como não há fiscalização, manutenção ou outro meio de 
segurança, muitas vezes se observa crianças brincando entre os equipamentos que se encontram abertos e sem nenhuma restrição efetiva de acesso.

De acordo com Peixoto, o sistema de dutos da Petrobrás que atravessa diversos manguezais e localidades da Ilha, a exemplo da comunidade de Porto dos Cavalos, configurase "num importante tensor ambiental, de perigo, ameaça e consequentemente, risco, com a possibilidade de rompimento, gerando vazamentos, contaminações ou explosões" (PEIXOTO, 2008, p. 162).

Segundo pesquisadores que atuam na região, o descaso com as comunidades da llha de Maré por parte desses empreendimentos revela um grave cenário de injustiça social, ambiental e cultural, uma vez que não reconhece sua história, o seu modo de vida e suas necessidades. "Não foi comunicado, negociado, nem outro tipo de diálogo, simplesmente, chegaram e colocaram suas máquinas, como se o território fosse deles. Negam nossa existência, nossa atividade e querem negar o nosso direito a vida" (DEPOIMENTO PESCADORA DA ILHA - Pesquisa de Campo, 2016).

Com a descoberta e extração do Petróleo no Recôncavo Baiano e, posteriormente, a chegada da RLAM, cria-se a necessidade da instalação de outras indústrias e serviços, a destacar o terminal da Petrobrás, denominado Terminal Marítimo Almirante Alves Câmara (TEMADRE), criado em 1957, na llha de Madre de Deus, na época pertencente ao município de Salvador (em 1989, cria-se o município de Madre de Deus). Considerado "a terceira maior unidade aquaviária operada pela Transpetro no Brasil em capacidade de armazenamento (66o mil m³) e maior do Nordeste" (TRANSPETRO, 2015, s/p), o TEMADRE foi o primeiro "terminal aquaviário do Sistema Petrobras a entrar em operação. Atualmente, é o principal ponto de escoamento da produção da Refinaria de Mataripe (RLAM), cujos derivados abastecem as regiões Norte e Nordeste do País" (TRANSPETRO, 2015, s/p).

De acordo com os pescadores da llha, uma das maiores preocupações existentes em relação ao TEMADRE refere-se ao derramamento/vazamento de produtos químicos nas águas da Baía e à contaminação de peixes e mariscos. Segundo relatos dos mesmos, nos últimos anos, diversos derramamentos ocorreram nas águas da BTS e isso tem prejudicado, a curto e médio prazo, a prática e a qualidade dos pescados capturados. Além disso, o tráfego de navios dentro do território pesqueiro, além de ameaçar a segurança dos pescadores e marisqueiras, interfere diretamente no desenvolvimento de suas atividades. 
Se, durante a década de 1950, a instalação da RLAM e do TEMADRE já era considerada uma grande ameaça à dinâmica natural da Baía e das comunidades tradicionais ali existentes, é nas décadas de 1960/70 que este cenário é fortemente agravado, devido à criação do Centro Industrial de Aratu (CIA) e à formação do Complexo Petroquímico de Camaçari (COPEC) em 1978.

Criado pelo governo do Estado a partir de incentivos fiscais administrados na época pela Superintendência para o Desenvolvimento do Nordeste (SUDENE), o CIA contém, além do Porto de Aratu, mais de 200 empresas dos setores químico, metalúrgico, fertilizantes, eletroeletrônicos, alimentício, plásticos, bebidas, têxtil, serviços, comercio, termelétrico, minerais, cosméticos, entre outros.

Com a inserção do CIA e de suas unidades fabris nas décadas de 1960/70, a necessidade de viabilizar o escoamento da produção aumentou significantemente e, assim, a ideia de construir um porto para apoiar o desenvolvimento industrial do Estado materializou-se nas obras de construção do Porto de Aratu.

Inaugurado no ano de 1975 e responsável por mais de 60\% da carga transportada no estado da Bahia por via marítima, o Porto de Aratu foi construído ainda no "governo do presidente João Batista Figueiredo entre os anos de 1971 e 1975, época em que ainda não se cogitava legislação ambiental e, portanto, foi implementado sem nenhum tipo de estudo de impactos socioeconômicos e ambientais" (MONTEIRO, 2014, p. 6o). Localizado na entrada da Baía de Aratu, o porto "cumpre o papel de indutor do processo de desenvolvimento industrial da Bahia, viabilizando os dois principais polos do setor existentes no Estado: o Centro Industrial de Aratu (CIA) e o Pólo Industrial de Camaçari" (CODEBA, 2016, s/p).

Além do porto de Aratu e do TEMADRE, outros grandes terminais portuários estão inseridos dentro do BTS. Nesse sentido, é importante destacar a existência do Complexo Portuário da Baía de Todos os Santos, formado pelos portos públicos de Salvador e Aratu e pelos sete Terminais de Uso Privado (TUPs): Terminal Madre de Deus (TEMADRE), TUP Ponta da Laje (Terminal da Ford), Terminal Marítimo Dow Aratu, Terminal Portuário Cotegipe, TUP Usiba, Terminal de Regaseificação da Bahia e Estaleiro Paraguaçu (em construção). 
Criados com o propósito de suprir a demanda de escoamento dos produtos especializados e produzidos pelas indústrias existentes na BTS, os Terminais de Uso Privado (TUPs) foram responsáveis pela movimentação de 23.294.852 toneladas, no ano de 2016. Mais de 880 navios atracaram nos TUPs, durante o referido ano (CODEBA, 2017).

Se observarmos a Figura 01, onde são apresentados os possíveis limites do território articulado das comunidades pesqueiras da llha de Maré, notaremos que todos os terminais que integram o Complexo Portuário da BTS encontram-se inseridos neste território. A região da Baía de Aratu, por exemplo, é utilizada, pela maioria das comunidades, para o desenvolvimento da pesca e da mariscagem. "Em Aratu tem muita coroa boa e tem muito pesqueiro, até hoje tem lugar que a gente considera um dos melhores pontos de pesca e olha que lá está só a poluição, imagine antes de vir essas indústrias todas" (ENTREVISTA MARISQUEIRA - Pesquisa de Campo, 2017).

Observa-se, ainda, através dos relatos das comunidades e diversos estudos científicos sobre a região, que a inserção dos poços de petróleo, da RLAM, do Porto de Aratu e demais TUPS, do CIA e do Pólo Industrial de Camaçari na região da BTS tem ocasionado diversas alterações nas condições naturais da Baía e, conjuntamente, na vida das comunidades da Ilha da Maré. Esses empreendimentos "além de conflitarem em relação ao espaço físico, são responsáveis por grande parte dos contaminantes dos frutos do mar e do ar, em toda a Baía de Todos os Santos" (MONTEIRO, 2014, p. 17).

É importante pontuar que as restrições decorrentes da instalação dos empreendimentos não se resumem à estrutura física, englobam também a dinâmica de movimentação de navios e cargas dentro da BTS, que ocorre em áreas tradicionalmente utilizadas pelos pescadores. Como se trata de embarcações de grande porte, a velocidade e a ondulação provocada pelas mesmas acabam colocando em risco o trabalho de centenas de pescadores e marisqueiras que manobram, diariamente, suas embarcações artesanais e artes de captura. Muitas vezes, estes são obrigados a optar entre desenvolver suas atividades com os riscos existentes (vida e perda de material de pesca) ou procurar outros espaços, "perdendo" parte de seu território de pesca. "O canal de navegação dos grandes navios cargueiros que transportam produtos para os portos dentro da baía de Aratu [...] é inclusive a mesma rota das embarcações artesanais que se direcionam para a região" (MONTEIRO, 2014, p. 56). 
Na pesquisa de dissertação intitulada "Bahia de Todos os Santos: Vulnerabilidades e Ameaças" foi verificado que onde há terminais portuários e tráfego de navios e cargas, também se encontram os maiores indicadores de polvição da BTS (PEIXOTO, 2008). Nesse sentido, é importante destacar que só no ano de 2016, aproximadamente 2.126 navios passaram pelo complexo portuário da BTS, sendo 624 no Porto de Aratu, 883 nos Tups e 619 no porto de Salvador (CODEBA, 2017). Ou seja, 2.126 navios estiveram trafegando dentro do território pesqueiro das comunidades tradicionais da llha de Maré.

Não obstante, as inúmeras questões sociais, ambientais e econômicas que envolvem a Petrobrás, a RLAM e os terminais portuários existentes na BTS, a mesma ainda é o palco de inúmeros empreendimentos industriais dos diversos segmentos. Desde a criação do Centro Industrial de Aratu (CIA), no final da década de 1960, e a formação do Complexo Petroquímico de Camaçari (COPEC), na década de 70, mais de 250 indústrias (químicas, metalúrgicas, mecânica, farmacêutica, automobilísticas, alimentícias etc.) se instalaram na região (HATJE etal, 2009).

Cada novo empreendimento deste porte que se instala na região traz um passivo socioambiental de grandes proporções, uma vez que apesar de afetarem diretamente o território pesqueiro da comunidade de llha de Maré, geralmente nos relatórios de impactos ambientais destes empreendimentos a comunidade da ilha fica excluída, uma vez que as análises técnicas consideram apenas a localização física das comunidades e não a abrangência territorial tradicional (MONTEIRO, 2014, p. 62).

Durante as pesquisas de campo foi possível observar que a inserção dessas atividades gerou uma nova dinâmica socioeconômica e espacial na BTS e, com isso, despertou o interesse de outros setores que também passaram a investir e ocupar a região: o setor turístico e imobiliário com a construção de hotéis, pousadas, casas de veraneio e restaurantes; o setor agrícola com o desmatamento de diversas áreas de floresta para a inserção de pastos e/ou cultivos específicos, etc.

A inserção do setor turístico e imobiliário, por exemplo, tem ocasionado diversas alterações na llha e na região da BTS. Com a construção das indústrias, diversos trabalhadores passaram a procurar, na Ilha, serviços de alimentação, hospedagem, moradia e lazer. 
Desde a década de 1960, a parte sul da llha encontra-se ocupada por diversos restaurantes, pousadas e serviços voltados ao turismo e lazer. Atualmente, nas comunidades de Neves e Itamoabo, a maioria das casas pertence a pessoas de outros municípios, turistas e veranistas. Muitos nativos acabaram vendendo ou trocando suas casas com funcionários das indústrias ou pessoas de outras regiões. "Em Neves tem no máximo 25 famílias de nativos e em Itamoabo, umas 11. A maioria hoje mora nos bairros periféricos de Paripe, Ribeira, Cidade Baixa, Suburbana, em Salvador" (DEPOIMENTO PESCADORA, Ilha de Maré, Pesquisa de Campo, 2017).

Outro problema histórico existente na Ilha de Maré refere-se à privatização do espaço por fazendeiros e/ou investidores da região. Há algumas décadas, a llha do Topete se tornou uma propriedade privada, que tem sido utilizada para veraneio e a realização de grandes eventos. Inserida dentro do território pesqueiro local, a pequena Ilha é "circundada por coroas utilizadas pelas marisqueiras como sítio de extração de recursos e pelos pescadores como pesqueiros e [...] como ponto de apoio onde o pescador pode encostar sua embarcação em 'terra firme'"' (MONTEIRO, 2014, p. 46).

Destaca-se ainda que, para a construção do empreendimento existente no Topete, áreas de manguezais foram desmatadas, partes do cascalho das coroas foram retiradas e algumas cercas foram inseridas no lugar, restringindo o acesso das comunidades a um espaço historicamente usado para o desenvolvimento de suas atividades. Desde a sua privatização, não é mais permitida a aproximação de pessoas para a realização da pesca e da mariscagem.

Observa-se que o conjunto de atividades desenvolvidas e planejadas para a região tem colocado a BTS e as comunidades da llha de Maré num cenário cada vez mais crítico e ameaçador. Pois, além das restrições de acesso aos espaços "tradicionalmente utilizado para pescar ou mariscar ou do risco enfrentado durante o deslocamento, a comunidade enfrenta ainda um grave problema que é a contaminação dos recursos e do ambiente" (MONTEIRO, 2014, p. 68). A inserção desses empreendimentos impôs às comunidades da llha de Maré uma dinâmica de uso e controle do espaço que, além de negar as suas especificidades, provoca a degradação massiva do meio ambiente, interferindo diretamente no desenvolvimento de suas atividades. É desse cenário que emergem as principais disputas e conflitos territoriais vivenciados pelos pescadores e marisqueiras de Maré. Conforme apresentado, trata-se de 
disputas históricas e que têm demandando, cotidianamente, das comunidades a criação de estratégias de luta e defesa de seus territórios.

\section{As estratégias de luta e defesa dos territórios}

Durante os últimos anos, pescadores e marisqueiras da llha de Maré organizaram e/ou participaram de diversas ações, a destacar:

a) passeatas e ocupações em alguns empreendimentos existentes na BTS;

b) seminários locais, estaduais e nacionais;

c) audiências públicas nas comunidades da llha;

d) grupos de estudo com pesquisadores de distintas Universidades e áreas do conhecimento;

e) cartas de manifesto;

f) denúncias em programas de rádio, TV e sites;

g) participação em eventos científicos na Bahia e outros estados do país;

h) reuniões com diversos órgãos públicos;

i) discussões com representantes das indústrias presentes na BTS; $x$ ) mapeamentos sociais temáticos;

j) estudos ambientais; xii) filmes e documentários; xiii) cursos de formação de liderança, etc.

Essas ações, além de demonstrarem a resistencia das comunidades frente aos diversos conflitos vivenciados com os empreedimentos existentes na BTS, reafirmam a necessidade da regularização do território local. Afinal, trata-se de décadas lutando diariamente para provar ao Estado, empresários e órgãos ambientais que o modelo de desenvolvimento historicamente empregado na BTS, além de estar degradando uma área de grande importancia ambiental do Estado (BTS), ameaça diretamente a vida de inumeras familias pesqueiras. É no âmbito das ações de resistência, luta e defesa do território local, que as comunidades da llha passam a reinvindicar, junto ao Estado, alguns processos de regularização territorial, a destacar o de terras quilombolas.

A discussão sobre a questão quilombola na llha de Maré, especificamente, sobre seus direitos territoriais, inicia, no final da década de 1990, quando as contradições e disputas que 
envolvem o território local ganharam novas e distintas proporções. Trata-se de um período no qual a luta pela terra com os fazendeiros se expandiu e tornou-se cotidiana, envolvendo queima e derrubada de casas, expulsões das roças, ameaças, exploração, prisões, entre outros conflitos. Além disso, com a chegada da Petrobrás, da RLAM, do CIA e demais empreendimentos na BTS, criam-se novas dinâmicas e usos do espaço que fogem do controle das comunidades e interferem diretamente no desenvolvimento de suas atividades. Portanto, é no âmbito do processo de luta e criação de estratégias de defesa do território que as comunidades de Maré, através de organizações locais, passam a reivindicar, a regularização do território quilombola ao Estado.

Para Santos (2017), ao analisarmos a formação de territórios quilombolas, devemos levar em conta: "o contexto regional e histórico, a origem dos grupos, sua relação com a opressão sofrida historicamente, a existência de conflitos fundiários, a situação jurídica das terras onde essas comunidades formaram seus territórios" (SANTOS, 2017, p. 121). As comunidades tradicionais da Ilha de Maré têm nas bases de sua constituição o tripé latifúndio, monocultura e escravidão. É decorrente desse modelo de sociedade senhorial, baseado na propriedade de terras e negros escravizados, que ocorre a ocupação da Ilha. Explorados durante décadas, sem terra e sem trabalho, os ex-escravos encontraram no mar, no mangue e nas florestas, a sua principal fonte de sobrevivência e, posteriormente, renda.

Trata-se, portanto, de um coletivo de sujeitos que construíram, no decorrer do processo de ocupação sócio territorial da llha, uma identidade étnica (grupo social que possui especificidades culturais, linguísticas, históricas etc. comuns) que thes permite se autoidentificar enquanto comunidades quilombolas e, que têm na prática da pesca artesanal, a sua principal e, muitas vezes, única fonte de renda (ARRUTI, 2006).

De acordo com os integrantes do Conselho quilombola da Ilha, a abertura do processo de regularização do território quilombola iniciou-se no ano de 2002, quando seis das onze comunidades existentes na Ilha realizam o pedido da Certidão de Auto Reconhecimento na Fundação Cultural Palmares, obtendo-a no ano de 2004. São estas: Bananeiras, Maracanã, Porto dos Cavalos, Martelo, Ponta Grossa e Praia Grande. De posse da certificação, as comunidades retomaram as discussões na llha e, no ano de 2008 , solicitaram a abertura do processo administrativo no INCRA/BA. Atualmente, o processo encontra-se com o Relatório Técnico de Identificação e Demarcação publicado no Diário Oficial da União (2017) e em fase 
de recursos e contestações. De acordo com os dados do processo, trata-se de 404 famílias e uma área de 644,7356 hectares (do total de 1.130,3536 ha que constitui a Ilha), constituída por terras ocupadas pelas comunidades pleiteantes, posses, propriedades particulares registradas em Cartórios e empreendimentos privados. (INCRA, 2017) (Figura 02)

Na figura 02 é possível observar que o perímetro que constitui o território reivindicado é ocupado, em mais de 90\%, pelas fazendas Martelo, Maracanã, Bananeiras, Oratório e Cruz. É nas proximidades e/ou dentro das fazendas que muitas famílias residem e desenvolvem as atividades da agricultura, extrativismo vegetal e a pecuária. Portanto, a demora em emitir a titulação significa conviver mais alguns anos, com restrições de acesso e uso ao território.

Além da demora, as comunidades também destacaram as "restrições" existentes no perímetro reivindicado, visto que apenas seis comunidades pleitearam a regularização: Bananeiras, Maracanã, Porto dos Cavalos, Martelo, Ponta Grossa e Praia Grande. As comunidades do Botelho, Itamoabo, Neves, Santana e Caquende, apesar das reuniões e mobilizações realizadas pelas lideranças locais, optaram por não realizar o pedido de certificação e, portanto, não se encontram incluídas no processo. Cabe destacar, ainda, que a comunidade de Praia Grande, também por esse motivo, só reivindicou a área da Fazenda Cruz, ficando boa parte do espaço da comunidade também de fora do pleito. 
Figura 2 - Poligonal do Território Quilombola reivindicado pelas comunidades da llha de Maré.

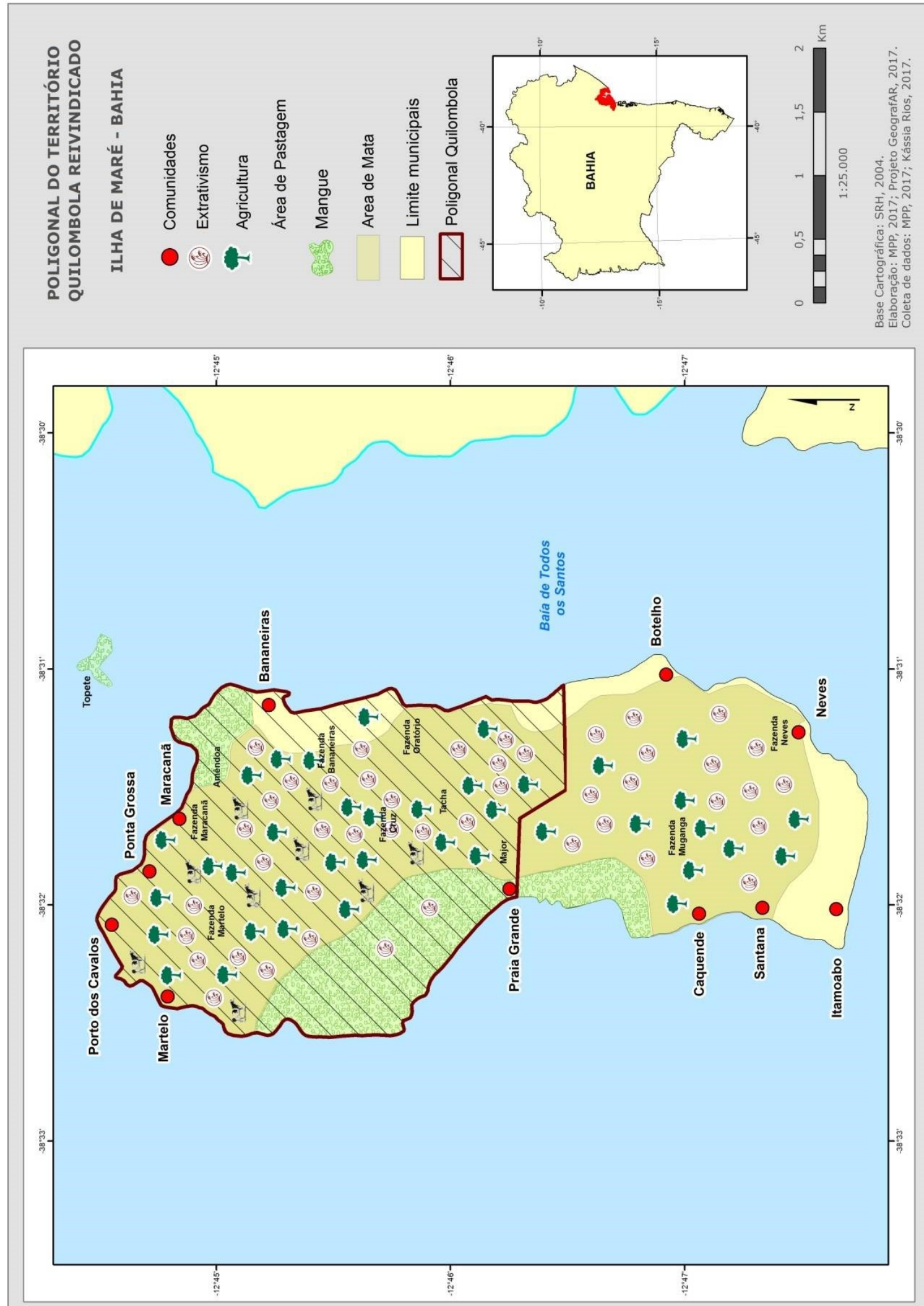

Fonte: MPP, 2017; Projeto GeografAR, 2017. 
Para os pleiteantes, essa negativa é decorrente do histórico de transformações vivenciado na região da BTS, pois, com a chegada da RLAM, Porto de Aratu, CIA e demais empreendimentos, essas comunidades passaram por um processo de reorganização espacial, destinado a atender à demanda (moradia, alimentação, lazer, comércio etc.) dos novos trabalhadores. Em poucos anos, estimuladas por forças regionais/locais, essas comunidades se transformaram em espaços estratégicos ao desenvolvimento do turismo e, nesse processo, muitos nativos acabaram vendendo/trocando suas casas com pessoas de outras regiões.

A demora de cada etapa tem sido um dos motivos de grande preocupação das comunidades, pois, enquanto o processo tramita, o território continua a ser ocupado por novos empreendimentos, aumentando o cenário de crises vivenciadas pelos moradores da Ilha.

\section{Considerações finais}

O histórico de crises, materializado em inúmeros conflitos e disputas territoriais vivenciado pelas comunidades tradicionais pesqueiras e quilombolas da Ilha de Maré é compreendido enquanto uma das dimensões na qual questão agrária se materializa no Estado da Bahia. Fruto do processo desigual e contraditório do modo de produção capitalista, tal questão é caracterizada por um histórico de invisibilidade e pela eminência de inúmeras desigualdades e racismos sociais, ambientais e culturais.

Responsável por cerca de $70 \%$ do pescado produzido no Estado e considerada a principal fonte de renda de mais de 131 mil pescadores(as) artesanais e cerca de 600 comunidades tradicionais pesqueiras estimadas na Bahia (MPP, 2016), a pesca artesanal nunca foi pensada, planejada e/ou priorizada na gestão do Estado. Pelo contrário, durante décadas, a atividade da pesca artesanal tem sido intensamente invisibilizada e, com isso, o capital, através do próprio Estado, de empresas privadas (nacionais e internacionais) e/ou particulares tem ocupado e degradado os territórios pesqueiros, num ritmo cada vez mais crescente.

Mesmo se tratando de territórios legais, tais como Áreas de Proteção Ambiental (APA), Reservas Extrativistas e/ou territórios quilombolas etc., observa-se que os espaços de uso das comunidades se tornaram áreas de interesse estratégico ao desenvolvimento do 
capital. Isso tem implicado aos pescadores(as) artesanais uma necessidade cotidiana: a luta pela efetivação de seus direitos e, principalmente, pela permanência nos territórios pesqueiros.

Em Ilha de Maré, a poluição química das águas e dos pescados, a especulação imobiliária, o aterramento de rios, a privatização das águas, ilhas e coroas, a construção de portos, estaleiros e piers, a realização de dragagens e o derramamento de produtos químicos, por exemplo, são alguns conflitos vivenciados cotidianamente pelas comunidades e que interferem e ameaçam diretamente a prática de suas atividades. Observa-se que o conjunto de atividades desenvolvidas e planejadas para a região tem colocado a BTS e as comunidades da Ilha de Maré num cenário cada vez mais crítico e ameaçador. E o Estado, enquanto órgão regulador, ao invés de controlar tal situação, tornou-se um dos grandes investidores presentes na região.

Outro ponto específico, identificado nos conflitos vivenciados pelas comunidades da Ilha de Maré, é que muitos destes envolvem, principalmente, áreas que se encontram em processo de regularização como Território Quilombola, há mais de 12 anos. Enquanto não é emitida a titulação do território, novas disputas e conflitos territoriais vão se materializando cotidianamente. É frente a esse cenário de crises e disputas que as comunidades tradicionais pesqueiras e quilombolas têm buscado construir estratégias de resistência e defesa de seus territórios.

\section{Referências}

BAHIA PESCA. Dados da atividade pesqueira no estado da Bahia. Salvador: BP, 2014.

CARNEIRO, Fernando F. et al. Análise de Contexto Ilha de Maré - Salvador - BA. Observatório da Política Nacional de Saúde Integral das Populações do Campo, Floresta e Águas. UNB. Brasília/DF, 2014.

CARVALHO, Ingrid Gil Sales etal. Por um diálogo de saberes entre pescadores artesanais, marisqueiras e o direito ambiental do trabalho. In: Ciência \& Saúde Coletiva, 19(10), 2014.

CODEBA. Companhia das Docas do Estado da Bahia. Portos - Movimentação de Cargas 2016. Disponível em: http://www.codeba.com.br/eficiente/sites/portalcodeba/ptbr/porto_aratu.php?secao=porto_aratu_mercadorias_movimentadasAcesso em: Dez/2016. 
INCRA. Instituto Nacional de Colonização e Reforma Agrária. Processo 54160.001114/2008- 29: Regularização do Território Quilombola das Comunidades da Ilha de Maré. Banco de Dados. INCRA/ Salvador. 2017.

INCRA. Instituto Nacional de Colonização e Reforma Agrária. Dados comunidades Quilombolas - 2016. Banco de Dados. INCRA/ Salvador. 2016.

MIASB. Mapa da Injustiça Ambiental e Saúde no Brasil. Relatório de Ilha de Maré - 2014. Disponível: http://www.conflitoambiental.fiocruz.br/index.php?pag=. Acesso:Jul/2016.

MONTEIRO, Igor Ramos T. Modelagem etnoecológica do território da pesca artesanal em Ilha de Maré, Salvador-BA. 2014. 10of. Dissertação (Mestrado em Ciências Ambientais) - Universidade Estadual de Feira de Santana, Feira de Santana, 2014.

MPA, Ministério da Pesca e Aquicultura. Dados do Registro Geral da Pesca - Pescadores, Embarcações, Colônias, Associações, Sindicatos e Cooperativas. MPA, 2014.

MPA, Ministério da Pesca e Aquicultura. Boletim Estatístico da Pesca e Aqüicultura - 2008 e 2009. MPA, 2010a.

MPA, Ministério da Pesca e Aquicultura. Balança Comercial do Pescado 2009. MPA, $2010 b$.

MPP. Movimentos dos Pescadores e Pescadoras Artesanais. Pesca e pescadores artesanais no estado da Bahia. Oficina. Salvador, MPP, 2015.

MPP. Movimentos dos Pescadores e Pescadoras Artesanais. Identidade e Território das Comunidades Tradicionais Pesqueiras. In: Cartilha - Trabalho de Base da Campanha Pelo Território Pesqueiro. MPP. Pernambuco, 2012.

PETROBRÁS. Refinaria Landulpho Alves. Resumo Histórico - 2016. Disponível em: http://www.petrobras.com.br/pt/nossas-atividades/principaisoperacoes/refinarias/refinaria-landulpho-alves-rlam.htm. Acesso: Dez/2016.

PEIXOTO, José Augusto Saraiva. Bahia de Todos os Santos: vulnerabilidades e ameaças. (2008) 192f. Dissertação (Mestrado em Engenharia Ambiental Urbana) - Universidade Federal da Bahia, Salvador, 2008.

PROTS, C. Resex marinha versus pólo naval na baía do Iguape. In: Novos Cadernos NAEA. (UFPA) v. 13, n. 1, p. 47-70, jul. 2009;

SANTOS, T. R. Entre terras e territórios: Luta na/pela terra, dinâmica e (re)configurações territoriais em Bom Jesus da Lapa (BA). 2017. 303f. Tese (Pós-Graduação em Ciências Sociais) - Universidade Estadual de Campinas, São Paulo, 2017.

SPU. Secretaria do Patrimônio da União. Processo 04941.006072/2013-14: Regularização do Território Quilombola das Comunidades da Ilha de Maré. Banco de dados. SPU/BA, 2017.

SPU. Secretaria do Patrimônio da União. Decreto n 89/2010. Disponível em:http://www.planejamento.gov.br//patrimonio-da-uniao/legislacao/portarias/portariasarquivos-pdf/portaria-89-2010-tau.pdf/view. Acesso em: Jan/2017. 
TRANSPETRO. Petrobras Transporte. Maior terminal aquaviário do Nordeste completa 58 anos de operação. Imprensa - 2015. Disponível em:

http://www.transpetro.com.br/pt_br/imprensa/noticias/maior-terminal-aquaviario-donordeste-completa-58-anos-de-operacao.html. Acesso em: Dez/2016.

\section{Detalhes da autora}

\section{Kássia Aguiar Norberto Rios}

Doutora em Geografia pela Universidade Federal da Bahia; Professora Adjunta da Universidade Federal do Recôncavo da Bahia; Coordenadora do Grupo de Pesquisa Laboratório Interdisciplinar de Estudos em Comunidades e Territorios Tradicionais - LIECCTT (UFRB/CETENS/CNPq); Pesquisadora do Grupo de Pesquisa GeografAR - A Geografia dos Assentamentos na Área Rural (UFBA/POSGEO/CNPq). Email: kassiarios@ufrb.edu.br 